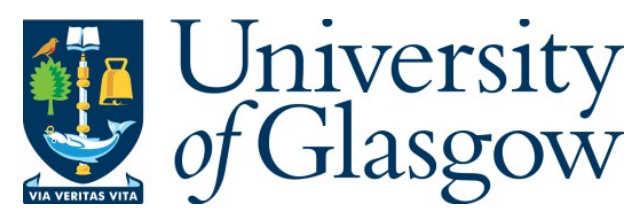

Hirsu, L. (2020) Lessons in response-ability: supporting social encounters by 'doing' language. Language and Intercultural Communication, 20(2), pp. 153-166.

(doi: $10.1080 / 14708477.2020 .1722148$ )

This is the Author Accepted Manuscript.

There may be differences between this version and the published version. You are advised to consult the publisher's version if you wish to cite from it.

$\underline{\text { https://eprints.gla.ac.uk/208927/ }}$

Deposited on: 10 February 2020

Enlighten - Research publications by members of the University of Glasgow http://eprints.gla.ac.uk 


\title{
Lessons in response-ability: Supporting social encounters by 'doing' language
}

\author{
Lavinia Hirsu \\ School of Education, University of Glasgow
}

\begin{abstract}
While many language programmes put the responsibility of language learning in the hands of refugees, few have developed approaches where the responsibility of language rests on both sides: with the refugees and the host communities. Building on rhetorical, intercultural and translanguaging theories, I present a peer-education model to show how it facilitated the emergence of social connections in translanguaging spaces. Participants focused on doing language: planning and delivering collective actions in their communities. I conclude by reviewing some of the principles of the programme that enable collective actiondriven language response-ability as a process towards sociolinguistic integration.
\end{abstract}

Nombreux programmes linguistiques confient aux réfugiés la responsabilité de l'apprentissage des langues et rares sont ceux qui ont développé des approches où la responsabilité de la langue repose des deux côtés: avec les réfugiés et les communautés d'accueil. Avec le support des theories rhétoriques, inter culturelles et de translanguaging, je présente un modèle d'éducation afin de montrer comment faciliter l'émergence de nouvelles connexions sociales dans des espaces de translanguaging. Les participants se sont moins concentrés sur l'apprentissage des langues seules et se sont lancés dans la production des langues: la planification et la réalisation d'actions collectives dans leurs communautés. Je conclus en proposant principes du programme qui facilitent la capacité de réponse fondée sur l'action collective en tant que processus d'intégration socio-linguistique.

Key words: intercultural communication, language responsibility, integration, refugees, linguistic hospitality

\section{Introduction}

Language learning is recognised as one of the fundamental elements in the process of social integration of refugees and asylum seekers. Without language access, people risk social isolation, while a range of emotional and cultural barriers prevent them from feeling a sense of belonging to their host communities (Scottish Government, 2018, p. 67). To move beyond language as a barrier, refugees and asylum seekers are expected to enrol in ESOL (English as a Second Language) classes, or any other forms of language support that would enable them to learn quickly and move into their new cultural and social environments. This is often framed as a task that will bring about individual 
social benefits (e.g., gaining access to jobs, public education systems and health services). However, by framing language learning as the responsibility of the Other, as a problem that refugees and asylum seekers need to address on their own (McPherson, 2010, p. 546), we miss considering the collective nature of language learning, the common duty to create language together, and the inbetween nature of language processes. A shift towards the space in-between people of different cultural, linguistic and social backgrounds becomes even more difficult in the context of worrying discriminatory and anti-ethnic public sentiments which continue to be on the rise (Barrett, 2016, p. ii).

Against a rhetoric that puts a premium on individual self-development (McPherson, 2010; Warriner, 2016), this article aims to present an alternative approach to the question of responsibility for language learning. The pilot programmei, Sharing Lives, Sharing Languages (SLSL), developed by the Scottish Refugee Council and local partners in an advisory role in January-June 2017, was designed to facilitate language encounters between refugees and host communities by engaging all participants in collective actions and making those involved responsible for each Other's language(s). In doing so, SLSL enabled its participants to create new social spaces by 'doing language' (or languaging). With collective actions as the main goal, SLSL placed the responsibility of language learning in-between individuals without the pressure of proficiency or linguistic competence. SLSL recognised that sociality begins with making the world together and language learning is an integrated and multi-dimensional process that unfolds through doing things with and in the immediate communities.

To present the SLSL approach, I draw upon two theoretical strands. First, I build on Giuliana Ferri's (2018) 'dialogic interaction' and Diane Davis' (2010) notion of response-ability to discuss the theoretical foundations of the programme. Second, I use research on translanguaging to show how SLSL's philosophy of shared responsibility was translated into 'doing language' (García, 2009). SLSL provides a model of practical translanguaging in multilingual environments where languaging emerges out of all the activities in which its participants are involved. As the external evaluator of SLSL, I examine the programme based on the Moment Analysis method (cf. Li Wei, 2011) and, in this article, I share some of these moments to illustrate the benefits and challenges encountered by its participants. Through the presentation of this programme, my goal is to bring forward the importance of collective and action-driven language responsibility as a process towards social integration and language support. SLSL demonstrates that such a responsibility is not just aspirational but can be delivered when the primary drive of human encounters is not to learn or teach a language, but to do things together for the benefit of all.

\section{Sharing Lives, Sharing Languages (SLSL): a holistic programme for peers}

The peer model of SLSL is one of a growing number of programmes for language 
learning based on the understanding that integration requires a holistic approach and it calls for human-centred and human-rights-driven processes (Ager \& Strang, 2008, p. 177). As outlined in the British Council report, Language for Resilience, opportunities for language programming have been developed in countries like Jordan, the Kurdistan Region of Iraq, Lebanon and Turkey. Various modelsii, ranging from home language-based learning programmes to skillbuilding, were tested and implemented with the same goal of fostering 'social cohesion and intercultural understanding' (Capstick \& Delaney, 2016, p. 5). With a focus on shared responsibility and learning together with host communities, these programmes aim at 'helping to forge new social networks and interaction with the wider community' (Capstick \& Delaney, 2016, p. 7). For instance, in Iraq (the Kurdistan Region), Mercy Corps delivered a programme that combined language learning with building social cohesion to mixed groups, which included refugees, internally displaced persons (IDPs) and host communities. While these programmes still place a great degree of emphasis on developing individual language proficiency, they also recognise that language learning requires and contributes to a sense of community building and, as such, it engages a collective response.

The pilot developed by the Scottish Refugee Council (SRC) over the January-June 2017 period had two aims. First, following the New Scots; Integrating Refugees in Scotland's Communities strategy, SLSL aimed to support New Scotsiii to form social connections with people in their communities from a variety of socio-cultural backgrounds. Driven by the motto integration from Day 1 ', the SRC believed that successful integration processes need to open up social interactions between different communities despite language proficiency. New Scots did not have to wait until they knew the English language in order to be able to make friends and to socialise with peers in their neighbourhoods, towns and cities. The second aim of the programme was to provide new contexts for language learning through the initiation of collective actions planned and delivered in a group format. This second aim, as I will show in the following sections, was one of the most critical aspects of the programme.

The two aims were designed to support Scotland's ESOL strategy 20152020 by reframing language learning within the model of peer education. Peer Educator Coordinators (PECs) administered and participated in the delivery of the programme within different communities across Scotland. In their areas, PECs identified Peer Educators (PEs) who helped form peer groups. The PECs trained the PEs so they could better understand the peer education model, the aims of SLSL and possible activities they could plan with their groups. The groups (5-12 participants/group) were led by one or two PEs and included local community members, as well as News Scots, who regularly attended English classes and sought more opportunities to practice new languages skills. Some groups were gender-specific while others were mixed, depending on the availability of the peers and their cultural/personal preferences. While the 
majority of News Scots shared Arabic as a common language, the peers, PEs and PECs were primarily fluent in English with some multilingual members drawing upon other languages (e.g., Polish, Arabic, Bulgarian). During the project, 61 peers regularly engaged in-group meetings while 110 participants took part in some of the activities planned by each group.

SLSL took as its core values the following: (1) peer learning which supports social engagement, connections with local communities and ongoing learning for personal growth (including the development of new skills and abilities); (2) collective actions as the catalyst for group activities; (3) appreciative inquiry that, '[i]nstead of identifying problems or things that are not working properly in different communities, [it] encourages people to build on what they can do to achieve their goals' (Hirsu \& Bryson, 2017, p. 10). Based on these principles, each peer group participated in meetings where they began identifying common likes, dislikes, needs, interests, and hobbies. They shared information about local services and resources and linked up with local stakeholders to move from planning to action. Groups planned a collective action, which helped them to form new social connections within their immediate communities and to deliver an activity (or series of activities) that would have a positive impact on the group, as well as the larger community. Such collective actions included organising a baking event, a community gardening project, a group walk, a family day out at the beach, and playing tennis.

\section{On the nature of language response-ability}

The previous description indicates a structured approach that enabled participants to come together. The set up of the programme built on two main theoretical strands: (1) a holistic understanding of language as response-ability towards the Other (here understood not as stranger or outsider but as a human being other than oneself), and (2) a practical understanding of language as doing, as a verb, as a way of making the world.

Both strands aimed to take language learning out of a prescriptive programmatic framework. Instead of proposing a pre-defined plan with language learning units or lessons, SLSL encouraged participants to engage in language encounters with peers from different linguistic and cultural backgrounds. This approach put into practice what Ferri (2018) describes as meaningful intercultural exchanges whereby people engage in 'dialogic interactions' - a type of dialogue that opens up when participants recognise each other's presence and acknowledge that, through communicative exchanges, meaning is coconstructed. Dialogic interactions are ethical encounters whereby language continuously establishes incomplete links between human beings. Language encounters are acts of opening oneself to the 'embodied presence' of others. In other words, languages are not just systems of rules, lists of words and grammars that we learn in order to access each other's worlds. A language encounter is about merging worlds in a continuous open-ended flow of 
communicating oneself to the other, 'an opportunity to discover the incompleteness of the self and to accept that the other can never be fully grasped' (Ferri, 2018, p. 89).

Ferri's notion of 'dialogic interaction' realises in practice what Diane Davis (2010) calls the natural response-ability that all humans have. Davis (2010) argues that '[c]ommunity is not the work of singular beings: it cannot be built and it is not a project or a product' (p. 8). The notion of community emerges when we all act upon 'a rhetorical imperative, an obligation to respond that is the condition for symbolic exchange' (Davis, 2010, p. 9). This is what responseability stands for: the human orientation towards the 'face' of the Other. Drawing upon the work of Levinas, Davis argues that we are all rhetorical beings oriented and ready to address each other even before we formulate language. Responseability is, therefore, a fundamental dimension of being human and, as such, already predisposes us to meet the other whether language (as articulated through words, grammar, sounds, etc.) is in place or not.

If through dialogic interactions (cf. Ferri, 2018), individuals enact this response-ability, how can a language programme like SLSL facilitate such interactions between individuals who do not share the same linguistic and sociocultural background? How can openness to one's language and new ways of being be ensured in both directions at the point of encounter, between New Scots and host communities? In Phipps's (2019) words, 'How, when we do not share language, do we work at this fragile edge between human beings, those whose language dominates those whose language is almost inaudible in cognitive terms?' (p. 42). How much can we programme language learning when our response-ability meets the barriers of communication on social, political, and communicative grounds?

To address these challenges, SLSL helped create translanguaging spaces where, to address one another, participants could draw upon all their resources, be they linguistic, corporeal, gestural, multimodal, etc. A growing body of research on translanguaging (Canagarajah, 2012; García, 2009; Helm \& Dabre, 2019; Paulsrud et al., 2017) has indicated that contexts where all resources are put together create new generative spaces where participants learn more than a target language. In translanguaging spaces, individuals use communicative resources in dynamic and fluid ways by moving beyond the boundaries of discreet languages. A creative and transformative process (Li Wei, 2018), translanguaging gives language users the possibility to explore their identities, values and language practices in relation to those of others with whom they interact.

Indeed, from a translingual perspective, language is not a noun but a verb, a way of doing language and of being in the world (García, 2009), an activity rather than a structure (Paulsrud et al., 2017). According to Helm \& Dabre (2018, p. 147), language is not 'a static system to be mastered (the structuralist view), but rather [...] an activity that people engage in, people acting upon one another 
through language.' While many translanguaging scholars point to this definition of language as a verb, few have explored the 'doing' nature of language in depth. As I show in the following sections, SLSL doesn't only support the notion of language as an open translanguaging space for action, but, more importantly, it makes collective action as the primary goal of all activities in which both New Scots and local community members were involved. By exploring different critical moments from the programme, I argue that SLSL pushed the notion of language as a verb by focusing on collective action as the means towards social and linguistic integration. This process shifted participants' attention away from traditional views of language learning and made apparent the important role of social bonds through which translanguaging encounters continuously emerge.

\section{Methodological and ethical matters}

As the evaluator of the SLSL programme, I collected a large corpus of data from three stages of data collection: (1) a pre-pilot stage (questionnaires with PECs and PEs, reflective self-evaluations, and initial assessment of activities); (2) the implementation of the project (feedback on participatory activities, group and individual assessment tools, session materials, observations and visit notes, individual and group reflections); and (3) post-pilot evaluation (case studies, interviews with individual PECs, questionnaires and interviews with PEs, focus groups with peers, peer surveys and mapping activities). During the project, I conducted regular visits to the sites where the peer groups met and collected photographs from group meetings shared by the PECs, artefacts and other materials created by the participants. Due to the novelty of the programme and the emergent relationships between participants, audio-recordings were not collected as the participants did not feel comfortable with this approach at the pilot stage of the programme. Examples of language exchanges were recorded via observations, reflection notes and indirect reporting from participants and myself. As these methods tend to gather subjective observations and interpretations, to strengthen the reliability of findings, I looked for patterns in the data to see if the reporting of findings was consistent across different data sources (e.g., my own observation notes compared to reflections from the PEs and PECs).

My role as programme evaluator changed several times during the project. During a focus group, for instance, I sat in a circle with participants who had little understanding of what research is. As I raised discussion points, the focus group conversation turned very mechanical: with short and polite answers, which were translated into even shorter affirmative or negative responses. In this context, I had to give up on my initial role so as to allow myself to become part of the group by sharing food and a cup of tea. Chatting with participants in this way enabled me to be less of a formal researcher and take on the less stable role of a peer in a web of growing relations, missed translations and incomplete messages. It is from this position of researcher-witness that I investigated the 
data collected, adding to it my ethnographic reflections.

In the process, I had to unlearn my role and, as language emerged around me, I took note of the ways in which social connections were formed. Instead of looking at/for 'data,' I began reflecting on the corpus and could see it not as a cohesive whole, but as recorded fragments of interactions, language bits, and unfinished thoughts. This approach to data resonates with Phipps' (2019) decolonizing methodology whereby, as researchers (and more specifically as researchers from the West), we need to resist closure and certainty given by the assumed power of 'data', and to open up the realm of 'findings' to collaborative dialogue and continuous exploration. As I conducted my 'evaluation' of the project, I became interested in the deeper assumptions and possibilities for social engagement that SLSL opened up.

In the spirit of this decolonizing methodology, I began paying attention to critical moments from the groups' encounters; i.e., 'spontaneous, impromptu, and momentary actions and performances (Li Wei, 2011, p. 1224). Based on Li Wei's moment analysis, I looked more carefully at turning points during the project that stood out through their 'distinctiveness and impact on subsequent events or developments' (Li Wei, 2011, p. 1224). Moment analysis allowed me to identify critical encounters that I witnessed and to reflect on the ways in which participants made sense of these moments through their metalanguaging, 'commentaries on the language user's own language practices as lived experience' (Li Wei, 2011, p. 1224). Instead of searching for coherent patterns of language behaviour, as Li Wei (2011) notes, I aimed to 'draw lessons' from shared experiences which provided insights into the distinctive approach of SLSL.

My selection of moments for analysis was guided not only by their memorable and significant nature, but also by their critical and creative potential. As turning points in the project, these moments encapsulate rich experiences that enable critical reflection. The moments are exemplary to the extent that they capture encounters where interpretations and research meaning can be assigned from multiple perspectives. Their second dimension, creativity, is equally important because critical moments become 'a reference point or frame' when they have the potential to change the conversation or theoretical lens on certain social and linguistic phenomena (cf. Li Wei, 2011, p. 1224). The critical moments I share in the following sections illustrate their creative nature in the ways in which peer actions and encounters help us see new dimensions of language responsibility.

At the same time, I propose that creativity of critical moments can also be related to their wider generative power. These moments have the ability to spark readers' imagination and open up new ways of relating to critical concepts and theoretical frameworks. While they occasion and guide my analysis, critical moments provide the opportunity for readers to read them as extracts, as fragments beyond the frameworks in which I embed them in this article. They 
can serve as starting points for imagining future encounters and, thus, new possibilities for engagement that I may not have commented on. In other words, the moments shared here invite the reader to reflection and critical engagement and, rather than locking down 'findings' and 'research meanings,' they extend the space of contemplation and response-ability to the reader as well.

While Li Wei's approach to moment analysis tends to put emphasis on individual experiences, in light of my concerns expressed in the previous sections, I will slightly depart from this approach and focus on moment analysis via experiences placed in the middle, in-between participants or in-between researcher and participants. This perspective allows me to present 'data' from the project in ways that protect the identity of peer-participants, while better reflecting on the nature of their encounters. All participants were involved in contexts of vulnerability due to uneven language abilities, social vulnerability, as well as emotional and practical challenges (e.g., being separated from the larger family, dealing with traumatic journeys and difficult resettlement processes, etc.). In this sense, ethical choices strongly guide methodological and analytical decisions in order to honour the collaborative relationships between the researcher and the participants, as well as to protect the identity of those who agreed to be part of this project (see Phipps, 2019).

\section{Lesson 1: Language encounters are languaging chains.}

The first peer sessions in the programme began almost similarly across the different groups by introducing the programme, its goals and the ultimate aim of the collective action. In most of these groups, greetings were presented in multiple languages, although at the beginning such formulas were shyly shared when not in English. In one women's group, a critical moment that seemed to change the dynamics between the participants was when the Arabic speakers prepared a mini lesson:

My observation notes: The session starts, we learn simple greeting words and phrases like 'hello', 'thankyou,' 'please' and 'how are you?' English-speakers make attempts to pronounce the phrases out loud, the Arabic-speakers laugh at the pronunciation and repeat the words in support [...] It almost feels like a regular language class but the laughter and side comments in multiple languages give the lesson a different vibe. During the break, I find myself in the middle of a cacophony of voices: some speak in Arabic, some in English, the room buzzes with voices. At any point in time, nobody knows and understands everything but that doesn't matter anymore. What I am witnessing is social bonding at its best.

English-speaking peer: Those words in Arabic that they taught us, I loved that. I took note of it and made myself flashcards that are now in my bedroom so I do remember some of those words. I would like to learn some more words and prepositions now so I can make some sentences in Arabic. I was taught a lot and 
I remark this moment of sharing greetings and other supporting phrases as a turning point in most of the peer groups because languages began to be understood differently by the participants. If during the introductory sessions English flowed more frequently and other languages seemed to be nodded at and shyly made heard of in the room, the rapport of languages changed when two Arabic-speakers stood up and owned the peer space by giving Arabic phrases in return for English greetings. Readers might argue that such an exercise was simply a way of matching up the English phrases with Arabic ones, a gesture to equalise the balance between the two languages, or nothing more than a translation exercise. However, I would propose that this Arabic lesson was a language response in a chain of one phrase calling for another, one language resource chaining and flowing from the other, a way of entangling oneself into the world of the other through exposure to new wor(l)ds.



Figure 1. Greeting words from a group

Scholarship on translanguaging focuses on the nature of resources that language users draw on in spaces where linguistic boundaries are contested and crossed over (García \& Li Wei, 2014; Paulsrud et al., 2017). Oftentimes, such descriptions are characterised by two important dimensions: on the one hand, the individual dimension is brought forward because language users are presented as drawing on their own resources, tapping into their own rich repertoires; on the other hand, these resources have a cumulative effect as they are made available by bringing them together in the translanguaging space. In the case of the SLSL sessions, we see these two dimensions when participants actively shared their own phrases as the first step towards addressing each other. 
At the same time, the peer sessions allowed for a third dimension of the translanguaging space to emerge: that of languaging chains, one phrase calling for another, one language resource echoing the previous one, a peer taking up the invitation to engage with the group by co-constructing a common space, of doing language together. The sharing of greetings and other supporting phrases was an act of hospitality that exposed peers to each other's sounds, but also to different levels of sociality and cultural ways of being, from an informal 'Hola!' (hello) in Spanish chained to greetings that wish good health and peace. By exchanging multilingual greetings, participants gained their first insights into the practice of welcoming and, in these language encounters, the first social bonds began to emerge.

To better understand this third dimension of the translangauging space, it is important to note that no one session had a linear and coherent agenda of language items or topics. Instead, one moment called for another, one phrase or word enchained a different sharing experience that included verbal and visual language, body language, objects and actions within the space of the peer sessions. For instance, in one group the PE began by randomly opening a visual dictionary to see what drew the attention of the group as a possible topic for discussion. Flipping through the pages, a peer noticed the image of a tooth and pointed to it using body language to express pain and thus, shared her story of what had happened to her the week before. Multiple conversations ensued about the different parts of the tooth and experiences with dentists in general.

Moments later, a different page from the dictionary moved the conversation to gardening and the group's plans to plant flowers in the community garden. The multimodal and non-sequential use of visuals, bodies and fragments in various languages characterised these translanguaging spaces where one experience or word called for and enchained a new sequence of signs and actions, symbols and other communicative resources. 

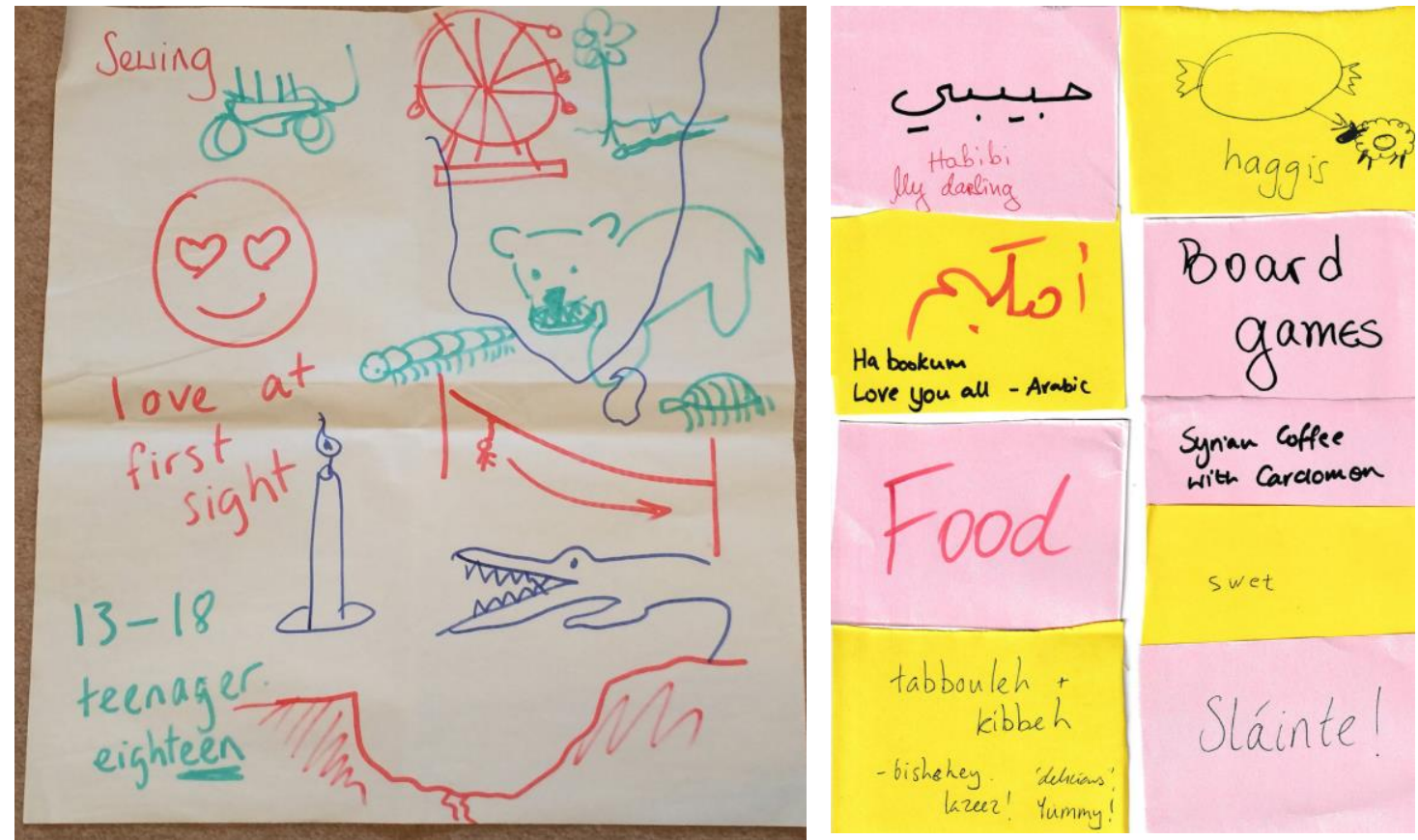

Figure 2. Example of languaging chains from two peer groups

Response-ability is not an ability or a competence, as the term might be traditionally understood. According to Davis (2010), response-ability is a form of exposedness in-between oneself and the Other, which translates into 'relationality' (Davis, 2010, p. 7), i.e., the languaging chains which bond people around resources that they are interested in exploring. Translanguaging, as it happened among the peers, enacted this relationality at the level of emergent connections, both human and communicative. The evaluation report of SLSL documents many instances of collective language learning where all participants added new vocabulary items to their repertoire; including Scottish conversational words (e.g., 'lad, 'lassie', 'laddy', 'ta ta!'), as well as more specialised terms related, among others, to sports and tennis in both Arabic and English (e.g., 'tennis', 'racket', 'net', 'ball'). But the spaces in-between peers were also visual, embodied and affective as Figure 2 indicates. It took peers through various idioms of talking about falling in love, and then enchained a conversation about the age at which you are said to fall in love in each culture, and how you express that in English in response to the sudden interest expressed by the New Scots in the group at the time of the conversation. These spaces where languaging chains emerged sometimes unexpectedly and in unpredictable directions filled up the initially unknown space in-between the peers, bonding them through incomplete sentences, fragmented stories and new scripts. Translanguaging spaces in the peer groups were indeed spaces where language resources flowed in multiple directions, guided by personal motivations, sudden interest and communicative curiosity. 


\section{Lesson 2: Translanguaging spaces are about making the world in the present together.}

PEC: The next activity was the creation of our learning flowers. As a visual way to keep track of the things the peers learn each week, we had the idea to create individual flowers where each petal is a different thing learnt and the colours of a petal can correspond to the different weeks of the session. For this week we made the centre of the flowers with each peer's name, the stem, and the leaf at the bottom with the same shared statement (for week 1 only). This week we learned 'We know everyone's shoe size.' In the weeks to come, the peers will have to come up with their own statements for the petals. The flowers were hung in the session room with cute flower pegs.

Peer: I felt I chatted with people during that activity more than in the group in some ways 'cause in this group sometimes we listen to one person talk but it's best when we do stuff in small groups or in a pair, doing an activity or just chatting, stuff that really forces you to try and communicate with people rather than sitting and listening to someone talk.

The title of the programme, Sharing Lives, Sharing Languages does not put language first. Sharing lives is at the core of peer meetings and language learning is woven into this vision of co-existence. The flower-making activity turning into collective action (i.e., planting a garden with a local charity) is one of the best examples of the philosophy behind this programme: language is doing, language is world-making, and language is the matter of life lived in each other's company. Each group of peers had as its ultimate goal a collective action, e.g., a communitybased cooking project, a visit to a men's shed, a game of tennis, a walk on the beach, a dance night, etc. These activities opened up the space between people within the same larger community and, more importantly, they created the opportunity to language together.

The concepts of language-as-a-verb and language-as-a-doing have made their way into current scholarly conversations on translanguaging spaces (see $\mathrm{Li}$ Wei, 2011; García \& Li Wei, 2014). However, in practice, few programmes have fully enacted and documented them. Reporting on a pilot project that involved English Languaging Workshops, Helm and Dabre (2018) discuss how dialogic sessions, similar to those in the SLSL programme, helped 'engineer' contact zones between refugees, migrants and various local members. Presenting languaging as a verb, the authors emphasise that encounters between participants in the project were 'an activity that people engage[d] in, people acting upon one another through language' (p. 148). This understanding of languaging, though, remains tied to intercultural and translingual dialogues, in the realm of discussions which inform and make social connections through the sharing of communicative resources. In this way, language-as-verb is less 
explored in terms of physical doings and activities.

Unlike English Languaging Workshops, SLSL puts language-as-doing at the core of all its activities, thus making all resources emergent in the peer sessions tied to bodies in action. In the example of the learning flowers, the individual answers with each person's shoe size came after the peers measured their feet and converted these metrics across different measurement and labelling systems.

Peer: When the group [members] were speaking about shoe size they were laughing because [one peer] had petite feet where [another peer's] feet were huge! The women shared many Arabic words and liked it when we tried to pronounce them.

The moment of language encounter emerged through the embodied presence of the peers. This way of being and sharing illustrates the dialogic nature of intercultural exchanges that Ferri (2018) calls for. Exposure to one's language is about exposure to one's body and the inter-action between those involved in the encounter. As Anderson and Macleroy note (2017), '[m]aking, crafting and sharing stories are at the heart of human experience and social transformation' (p. 497). What began with shoe sizes continued with number of tooth fillings, birth dates and locations, as well as breakfast preferences and hobbies. The petals which configured individual portraits were the result of collective meaning-making and life sharing moments, closely connected to what happened in the physical space of the peer sessions themselves.

The moment which initiated the creation of individual flowers also enchained a conversation about the possibility of a collective action in a community garden.

PEC: At the very end of the session, [the PEC] asked whether anyone in the group would want to help plant flowers in the garden at [a local charity] (where we hold the meetings). [...] The planting session would involve other local women involved with [the local charity] and its programmes. We also discussed that we could have a picnic/BBQ with Syrian food as part of this [...]

The symbol turned action reflects the potential outcome of Davis' (2010) 'inessential solidarity' - when people act upon their call to respond, then tangible, material outcomes become the imprint of those relationships. The entanglement of bodies, fragments of language (the flower petals) and actual activities in the community capture the creative collective-action approach to language encounters in the SLSL programme.

This approach, though, is not unique to this programme. Community gardens, for instance, and a focus on extending one's world through sharing language and physical labour have a long tradition (Moulin-Doos, 2014). 
Intercultural gardens as a model of integration have been developed to enable mutual respect between community members, to increase sociality across cultural differences and to 'create a community of place' (Moulin-Doos, 2014, p. 205). What is distinct about SLSL, though, is that the community of place has not been prescribed and the actions in each peer group emerged organically, based on the participants' interests and motivations. In a male group, for instance, a Syrian peer brought into the session his toolbox to share his craft and to learn the names of the various components in English. As a consequence, this spontaneous activity led the group to visit a men's shed and share skills on how the Syrian and Scottish workmen at the shed performed various activities according to their training.

By proposing collective action as the main goal, SLSL anchored translanguaging spaces into the present moment. Given that many News Scots coming into English carried with them difficult stories of rough journeys and broken family links, SLSL invited them to focus on the present and their immediate future. Many participants from the host communities joined the peer sessions to create a welcoming environment for New Scots and, as one peer noted, some had migrant experiences themselves which they wanted to share: 'I don't have any qualifications either, but because throughout time and through my children growing up [in Scotland], they were born here, so you know, it takes time. Inshallah, [my Syrian peers] will learn.' Recognising that fully sharing one's story requires a safe space and strong social bonds, SLSL provided all participants with a framework for building things together gradually, in the present, from welcoming greetings to a common imaginary space:

$P E$, commenting on the picnic with her group on the beach: It was very cold. The children were all in the water and the women were telling each other stories. Ahmediv said, 'Why is there no sun on the beach?' and I said, 'You know, Ahmed, this morning I had a word with Allah and I said: 'Allah, do you think we can have some sun on this beach?', and Allah said to me that the sun is in Syria. And the thing is we can say these things and we can laugh about it.

Knowing Ahmed's longing for his country, the PE proposes an imaginative exercise, which becomes a group joke due to the impossibility of the scenario. Instead of directly calling on Ahmed's life story, what the scenario of the peer captures is an intertwined and intimate relationship between Ahmed, the PE, Allah and the two locations, Scotland and Syria. In a non-invasive way, the truth of displacement and the walk on the cloudy beach become more bearable and memorable at the same time. The scenario of the sun gone from Scotland to Syria is a creative translanguaging moment of negotiating a hard journey. In an act of gentle sensitivity and response-ability, the PE invites her peer to inhabit a shared present in time and space via a new imaginary. This way of entangling stories with the immediate physical environment enabled peers to connect with one 
another and to see themselves as part of a chain of possible co-created relations grounded in common activities and new ways of being in the present.

\section{Lesson 3: Translanguaging spaces are about resisting the burden of language.}

If the two previous lessons show some of the positive interventions made by the SLSL model, Lesson 3 is a cautionary note about the challenges that such a programme had to address. This lesson is also a reminder that translanguaging spaces are not always positive experiences; the exposedness to others and the response-ability to others' communicative repertoires can sometimes result in precarious social links and unbalanced languaging experiences:

My observation notes: I meet this group in a public community room, a space quite large for the small size of the group. Three Arabic-speakers are gathered around the end of a long table. One English-speaker PE works closely on a worksheet brought by one of the New Scots from his English classes; the other PE sits at the other end of the table, almost isolated from the rest of the group. The first PE tells me his peer has begun to ask for help with his English homework from the English classes because the material is too hard, the vocabulary items are too difficult, the PE observes. The peer wants to learn English as quickly as possible to get a job. The session feels almost like a tutoring session although the second PE and two other Arabic-speaking peers join in at various points during the session with brief comments. While it is great to see the support the PE provides, I have a feeling this session is not fully enacting what SLSL sessions are meant to deliver. We start chatting about the programme and the PEs tell me in English about their challenge with this particular group where proficiency is so low they have had a hard time understanding each other.

PE: I didn't want to be the leader [...] we provided structure at the start and we even provided a plan every week but they [the Arabic-speaking peers] actually took over. We didn't say to them bring your stuff from the English classes.

PE: it's been a bit closer to the teaching model than I would have liked to do. I would have liked to do something less teacherly.

When peers did not share common language resources, the English-speaking peers in this group took it upon themselves to teach. Giving the gift of language was something within their power; therefore, the group's meetings turned into sessions focussed on conventional English teaching and learning. PEs tried to supplement regular English class material with knowledge built during the peer sessions. This approach changed the relationships between peers in that those who knew and had the language offered their knowledge to those who did not 
have the language, without fully recognising that placing language in between and not owning language were important means of achieving the same goals of the SLSL programme. In other words, the imperative to address the Other became a moral obligation to give language, rather than an openness to dwell between knowing and not knowing.

As Helm and Dabre note (2018), a translanguaging approach to doing language among refugees and host communities is meant 'to subvert the power dynamics whereby language learners, refugees and migrants, are positioned as defective or ineffective communicators of a target language' (p. 144). In this sense, a translanguaging approach is not only social but political. It aims to expose the arbitrariness of language boundaries, to go beyond the confines of language systems and rules, and to de-centralize the idioms of power.

Translanguaging spaces validate all the resources that each individual carries to make sense of one's world - materially, epistemically, affectively. For those who sit on the side of the idioms of power (i.e., English in the case of the SLSL project), an active decolonial methodology needs to be put in place in order to bring languages into balance (Phipps, 2019). According to Phipps, this requires decreation, i.e., a constant process to recognise one's position of privilege, giving oneself into a vulnerable position of not knowing, and opening towards the incompleteness of the self and Other.

This is risk-taking work and, in the case of the peer encounter presented at the beginning of this section, even with the best intentions, the PEs in the group could not accept their vulnerability in the encounter with Syrian peers. It was safer to inhabit the role of a teacher who aims to transfer a pre-determined body of knowledge (the English language) than to open up to other communicative resources that peers carried with them. It is important to note, though, that the preference for this teaching model came as a request from the Syrian peers themselves who initially understood the peer sessions as another 'classroom' space for learning English. For this reason, I see the missed opportunity to do language differently as the result of both groups of peers bearing the burden of language understood as a system of have and have nots.

As a teacher myself, I do not fault the 'teaching' model itself but this was not the framework that SLSL was designed to operate on. One of the PEs was very much aware that this was not the goal of the programme and the role did not bring the satisfaction of being with the peers that they had hoped for. The teacherly model that the PE referred to related to a certain kind of teaching that views meaning as transferrable from one individual to another, rather than an in-between exposedness to the Other. As Benseman (2012) suggests, being a good language teacher means, first and foremost, 'being human' by de-mystifying the 'teacher as expert' (p. 28). This vision of teaching points more towards Davis's and Ferris' notion of addressing the Other. However, for the PE and peers involved, the transmission model of the language teacher was very much the role that the participants looked up to. In this translanguaging space where language 
was viewed as a burden, a barrier between oneself and the other, something that can be passed on, the possibilities of doing things together were constrained to filling out the English worksheets.

\section{Conclusion: Open the door to thy neighbour!}

A growing body of scholarly work has already equipped us with frameworks on how to develop strong intercultural communication approaches and robust language learning programmes (Byram et al., 2016; Ferri, 2018; Parks, 2018; Rathje, 2007). Barrett (2016, p. iii) highlights the importance of working with individuals and their immediate communities to foster 'respect for the inherent dignity, needs and rights of all human beings.' A human-centred approach and a shared sense of responsibility and engagement are essential for enacting 'active intercultural democratic citizenship' (Barrett, 2016, p. iii). More importantly, Barrett notes, civic and political action for and in collaboration with disempowered and disadvantaged groups add a critical dimension to the work of intercultural citizenship.

Models of intercultural communication and competence have often been offered as remedy to communicative failures or linguistic-cultural dissonances. As I have demonstrated in this article, this approach is unnecessary if we are ready to admit that, as human beings, we all share a response-ability to address one another, a risky responsibility which is engrained in our way of being and acting in the world. What SLSL demonstrates is that language learning can be programmed differently: through the 'engineering' of translanguaging spaces (cf. Helm \& Dabre, 2018) where we can build human connections via languaging chains and collective actions. The three lessons presented in the previous sections offer insights into the benefits of supporting language learning through an approach to planning that goes back to simple, yet deeply humane, ways of reaching out to one another. The peer model of SLSL involves a profound form of sociality that seeks to bring people in the present moment, doing language together. For the participants, the programme translates and transforms overpowering discourses about language discrimination, linguistic inadequacy attributed to certain social groups and standards of linguistic practice as markers of 'good' citizenship. Instead, SLSL offers an alternative framework that places people in communicative contexts where all resources need to be combined and intertwined in order to be with one another and act in the world in meaningful ways.

From a theoretical standpoint, SLSL is also a generative example of the relationship between research and practice. While at the design stage of the programme, translanguaging principles and decolonial approaches to language learning underlined the structure and delivery of SLSL, these have not been explicitly discussed and elaborated on with the PECs or the PEs. Guided by a set of practical principles, the programme coordinators and the peers were driven by actions - actions that unfolded from commonly identified goals and 
motivations. Theory, in this sense, moved to the background and, as the programme developed, new dimensions of underlying theoretical principles became apparent through the planning of collective actions and the emergent responses of the participants.

In the context of linguistic and social integration, translanguaging spaces allowed us to learn more about the nature of these dynamic and fluid environments (Canagarajah, 2012; García 2009; Li Wei, 2011) where participants gradually engaged and enchained their individual stories with those of the group. The goal of sharing lives and languages was not so much to ensure belonging or linguistic learning by any pre-defined metric. Belonging may be too tall of an order when early encounters need to be set up first. With a more modest but equally important goal, SLSL relied on a gentler approach to making space for people to build new social connections through exposure to each other's presence and collective social action. A translanguaging space can facilitate such encounters when resources and people are set in motion. However, as Lesson 3 reminds us, translanguaging spaces are not devoid of conflict. Decentralising or breaking through the boundaries of language and their political baggage remains a struggle. In the context of the programme, explicit support on how to maintain these spaces open and resistant to any kind of closure (ideological, grammatical, motivational) is necessary so the work of social and meaning co-construction can continue.

As one peer observed, 'for me, there is a reminder of the old values we used to have here in Britain.' SLSL made peers think back to the idea of humanity as a village, to the values of having an extended family in the midst of your community, and to building lives together, or, in the words of Phipps (2019), to a way of working '[t]owards ecologies of neighbourliness.' SLSL shows how opening the door to thy neighbour is vital for the well-being of a community and has benefits for all those involved. At the same time, SLSL illustrates how such a simple goal is oftentimes challenged and closed down by the burden of language understood as a pre-defined transferrable system. To be open to the other requires that we work through the porous fabric of language(s) and to re-learn how to connect to people — in the moment — by doing simple things together.

\section{Acknowledgments}

I would like to thank the Scottish Refugee Council for their relentless work in welcoming New Scots and ensuring that their rights are protected and their experiences in Scotland are rich, positive and constructive. I would also like to express my deep gratitude to all the participants involved in the SLSL programme who shared their time and stories with great generosity.

\section{Disclosure statement}

No potential conflict of interest was reported by the author(s). 


\section{Notes on contributor}

Lavinia Hirsu is a Lecturer in the School of Education at the University of Glasgow. Her research and teaching are transdisciplinary as she works at the confluence of digital literacies, theories of cultural diversity and social inclusion, academic writing and translingual pedagogy. She has recently been involved in a series of international projects and has coordinated projects aimed at supporting translingual practices in multilingual environments. She recently co-edited a collection entitled Rhetorical machines: Writing, code, and computational ethics (University of Alabama Press, 2019).

\section{References}

Ager, A. \& Strang, A. (2008). 'Understanding integration: A conceptual framework'. Journal of Refugee Studies, 21(2), 166-191.

Auerbach, E., Barahona, B., Midy, J. Vaquerano, F., Zambrano, A., \& Arnaud, J. (1996). Adult ESL/Literacy from the community to the community: A guidebook for participatory literacy training. New York and London: Routledge.

Barrett, M. (2016). Foreword. In M. Byram, I. Golubeva, H. Hui, \& M. Wagner (eds.). From principles to practice in education for intercultural citizenship (pp. i vi). Bristol: Multilingual Matters. s

Benseman, J. (2012). Adult refugee learners with limited literacy: needs and effective responses. English Language Partners New Zealand. Aotearoa National Centre for Tertiary Teaching Excellence.

Byram, M., I. Golubeva, H. Hui, \& M. Wagner (eds.) (2016) From principles to practice in education for intercultural citizenship. Bristol: Multilingual Matters.

Canagarajah, S. (2012). Translingual practice: Global Englishes and cosmopolitan relations. London \& New York: Routledge.

Capstick, T. \& Delaney, M. (2016). Language for resilience: The role of language in enhancing the resilience of Syrian refugees and host communities. British Council.

Davis, D. (2010). Inessential solidarity: Rhetoric and foreigner relations. Pittsburgh: University of Pittsburgh Press.

Education Scotland. (2015). Welcoming Our Learners: Scotland's ESOL Strategy 2015 - 2020 The English for Speakers of Other Languages (ESOL) Strategy for Adults in Scotland 2015. 
https://education.gov.scot/Documents/ESOLStrategy2015to2020.pdf

Ferri, G. (2018). Intercultural communication: Critical approaches and future challenges. London: Palgrave Macmillan.

García, 0. (2009). Bilingual education in the 21st century: A global perspective. Malden, MA: Wiley/Blackwell.

García, 0. \& Li Wei (2014). Translanguaging: language, bilingualism and education. New York: Palgrave Macmillan.

Helm, F. \& Dabre, T. (2018). Engineering a 'contact zone' through translanguaging. Language and Intercultural Communication, 18(1), 144-156, DOI:10.1080/14708477.2017.1400509

Hirsu, L. \& Bryson, E. (June 2017). "Sharing Lives, Sharing Languages: a pilot peer education project for New Scots' social and language integration." Scottish Refugee Council.

McPherson, M. (2010). 'I integrate, therefore I am': Contesting the normalizing discourse of integrationism through conversations with refugee women. Journal of Refugee Studies, 23(4), 546-570.

Moulin-Doos, C. (2014). Intercultural Gardens: The Use of Space by Migrants and the Practice of Respect, Journal of Urban Affairs 36:2, 197-206, DOI:

10.1111/juaf.12027

Parks, E. (2018). Communicative criticality and savoir se reconnaître: emerging new competencies of criticality and intercultural communicative competence, Language and Intercultural Communication, 18(1), 107-124, DOI:

10.1080/14708477.2017.1401691

Paulsrud, B, Rosén, J., Straszer, B. and Wedin, Å. (Eds.) (2017). New perspectives on translanguaging and education. Bristol: Multilingual Matters.

Phipps, A. (2019). Decolonising multilingualism. Bristol: Multilingual Matters.

Rathje, S. (2007). Intercultural Competence: The Status and Future of a Controversial Concept. Language and Intercultural Communication, 7(4), 254266. DOI: $10.2167 /$ laic285.0

Scottish Government (2018). New Scots refugee integration strategy: 2018-2020. 
Scotland. http://www.gov.scot/Resource/0053/00530097.pdf

Warriner, D.S. (2016). 'Here, without English, you are dead': Ideologies of language and discourses of neoliberalism in adult English language learning. Journal of Multilingual and Multicultural Development, 37(5), 495-508. DOI: 10.1080/01434632.2015.1071827

Wei, L. (2011). Moment analysis and translanguaging space: Discursive construction of identities by multilingual Chinese youth in Britain. Journal of Pragmatics, 43, 1222-1235. doi: 10.1016/j.pragma.2010.07.035

Wei, L. (2018). Linguistic (super)diversity, post-multilingualism and Translanguaging moments. In A. Creese, \& A. Blackledge (Eds.), The Routledge handbook of language and superdiversity (pp. 16-29). London: Routledge.

\footnotetext{
i Based on the success of the pilot, the Scottish Refugee Council was able to secure funding to role out the programme across Scotland (October 2018-September 2020) in eight community groups and their respective local areas.

ii Community-based language programmes are neither new nor specific to the Syrian refugee crisis. As Auerbach et al. note (1996), participatory models based on bilingual instruction have emerged in 1989-1993. Communities have been considered as hubs of shared knowledge, while the idea of using bilingual mentors and community interns has been supported in different language programmes for immigrants and refugees (see Auerbach et al., 1996).

iii In the Scottish context, the term New Scots is attributed to refugees and asylum seekers in an effort to remove the social stigma of these identity labels and to include everyone under the same collective identity banner of the Scottish identity.

iv The name of the peer in this vignette is a pseudonym.
} 